\title{
Adherence of Probiotic Bacteria to Human Colonic Cells
}

\author{
Warnakulasuriya E.V. LANKAPUTHRA ${ }^{1}$ and Nagendra P. SHAH ${ }^{2}$ \\ ${ }^{1}$ Centre for Bioprocessing and Food Technology and ${ }^{2}$ School of Life Sciences and Technology, Victoria University of Technology, \\ Werribee Campus, PO Box 14428 Melbourne City Mail Centre, Victoria 8001, Australia
}

Received May 14, 1998; Accepted for publication, July 10, 1998

Bifidobacteria showed better adherence to monolayer $\mathrm{Ht}-29$ colonic cancer cells as compared with Lactobacillus acidophilus. Among bifidobacteria, Bifidobacterium infantis 1912 and B. longum 1941 showed highest level of adherence. Among L. acidophilus, strains 2400 and 2415 showed best adherence. Thus, in general, bifidobacteria may be preferred as dietary adjuncts over $L$. acidophilus. Proteins were found to be present in spent broth of all strains of adhering bacteria involved in adherence of probiotic bacteria to $\mathrm{Ht}-29$ cells. However, involvement of polysaccharides from bacteria and Ht-29 cells for adherence varied from strain to strain of probiotic bacteria. Polysaccharides produced by Ht-29 cell surfaces contributed to adherence than those originating from the bacterial cells. For $B$. infantis 1912 and $B$. longum 1941, polysaccharides of both bacterial and Ht-29 origin were involved in adherence. The molecular size of proteins involved in adherence varied among the strains of probiotic bacteria. In B. longum 1941 and $B$. infantis 1912 , a molecular size fraction of $30,000-50,000 \mathrm{kDa}$ was responsible for adherence. Adherence was mediated by a bridging structure (possibly a protein-polysaccharide structure) formed between bacterial and Ht-29 cells.

Key words: probiotic bacteria; adherence; human colonic cells; polysaccharide

\section{INTRODUCTION}

Probiotic bacteria such as Lactobacillus acidophilus and bifidobacteria belong to the natural flora of the intestine. The microflora of the gastrointestinal tract is comprised of about 400 different species of bacteria with a viable count of about $10^{12} \mathrm{cfu} / \mathrm{g}$ of intestinal content $(3,5)$. In addition to probiotic bacteria, other genera such as Streptococcus, Enterococcus, Bacteroides, Clostridium, Eubacteria, Peptococcus and Fusobacteria are present in the intestine (5). Some bacteria belonging to the genera such as Clostridia and Enterococci produce putrefactive products in the gut. The probiotic bacteria create a healthy equilibrium between beneficial and potentially harmful microorganisms in the gut (3).

Probiotic organisms are defined as "live microorganisms that produce beneficial effects to the host by maintaining a healthy equilibrium among the microflora of the gut." The desirable effects would be produced better if these organisms are able to adhere, multiply and colonise in the intestine (5). Adherence to the intestinal cell wall is an important prerequisite for colonisation in the gastrointestinal tract $(1,2)$. However, only a few species of lactobacilli such as $L$. gasseri $\mathrm{ADH}, L$. acidophilus $\mathrm{BG} 2 \mathrm{FO} 4$ and $L$. casei $\mathrm{GG}$ have been studied for their ability to colonize in the gut. Similarly, among bifidobacteria, B. breve, B. longum, B. bifidum and $B$. infantis have been studied for their ability to colonise in the gut (1). Coconnier et al. (2) reported that an ad- hesion promoting factor was present in the supernatant of spent broth of a human isolate of $L$. acidophilus BG2FO4. This factor was reported to promote adhesion of poorly adhering $L$. case $i \mathrm{GG}$. Coconnier et al. (2) reported that $L$. plantarum produced a protein like substance which promoted adherence of this organism to Ht-29 cells. Mukai and Arihara (4) reported the presence of lectin binding glycoproteins on the cell surface of $L$. acidophilus.

In this study, 6 strains of $L$. acidophilus and 9 species of bifidobacteria were studied to determine their level of adherence to human colonic carcinoma cell line $\mathrm{Ht}-29$. The effect of bacterial or carcinoma cellular proteins and carbohydrates on the level of adherence was also studied. Light and electron microscopes were used to examine the level and nature of adherence of probiotic bacteria to the Ht-29 cells.

\section{MATERIALS AND METHODS}

Microorganisms and Ht-29 cells. Pure cultures of 6 strains of $L$. acidophilus and 9 species of bifidobacteria were obtained from the Dairy Research Laboratory, Division of Food Science and Technology, Commonwealth Scientific and Industrial Research Organization (CSIRO), Highett, Australia. An Ht-29 colonic carcinoma cell line was obtained from the American Type Culture Collection (Rockville, USA).

Preparation of Ht-29 cells for adherence assay. The $\mathrm{Ht}-29$ cells were propagated in McCoy-5A medium (Sigma Chemical Company, Warrandyte, Australia) and 
passaged 2 times. The cells in confluent stage were separated from each other by treating with trypsin $(100 \mathrm{mg} /$ $\mathrm{ml}$ ) for $10 \mathrm{~min}$. The cells were centrifuged $(2,000 \mathrm{rpm}$; $4^{\circ} \mathrm{C}$ ), the trypsin solution decanted and resuspended in McCoy-5A medium containing 20\% foetal calf serum (Sigma). Sterile glass cover slips were placed on the bottom surface of sterile 8 well cell culture plates and 1 $\mathrm{ml}$ aliquot of freshly prepared cell suspension was pipetted into the wells to allow the cells to settle on the upper surface of the glass cover slips. These culture plates were incubated at $37^{\circ} \mathrm{C}$ for $2-3$ weeks in the presence of $10 \% \mathrm{CO}_{2}$, and the culture medium was changed daily. No antibiotics were added. When the monolayer cells became confluent, the culture medium was pipetted out leaving the cell layers attached to the cover slips. These cell layers were used for adherence assays and microscopic studies.

Preparation of probiotic bacteria for adherence assays. The probiotic bacteria were grown separately in MRS broth without aeration for $18 \mathrm{hr}$ at $37^{\circ} \mathrm{C}$ and the cells were separated by centrifuging $(5,000 \mathrm{rpm}$; $10 \mathrm{~min}$ ) in $10 \mathrm{ml}$ tubes. The supernatant was decanted and stored in a refrigerator until used. The cell pellet was washed with phosphate buffered saline (PBS, pH 7.0 ), centrifuged, resuspended in $10 \mathrm{ml}$ of PBS and stored in a refrigerator.

Adherence study of probiotic bacteria to Ht-29 cells using a light microscope. One millilitre aliquot of probiotic bacterial cells suspended in spent MRS broth, fresh MRS broth or spent MRS broth treated with trypsin or sodium periodate was pipetted into the wells of the cell culture plates of Ht-29 cell layers with glass cover slips. The bacterial cells were allowed to contact with $\mathrm{Ht}-29$ monolayer cells and incubated for $2 \mathrm{hr}$ at $37^{\circ} \mathrm{C}$ in presence of $10 \% \mathrm{CO}_{2}$. After incubation, the wells were gently washed 6 times with PBS. This step was necessary to remove any loose bacterial cells that did not adhere to the Ht-29 cells properly. After rinsing, the monolayer cells were fixed by pipetting $2 \mathrm{ml}$ of cold $\left(\sim 5^{\circ} \mathrm{C}\right)$ methanol for $20 \mathrm{~min}$. After removing the methanol, the cover slips containing Ht-29 monolayers were air dried and stained by flooding with crystal violet solution for $10 \mathrm{sec}$ and with Gram's iodine solution for $15 \mathrm{sec}$. Shorter exposure times were used in order to prevent over staining of Ht-29 cells. Each stain was rinsed with water followed by rinsing with $95 \%$ ethanol for $30 \mathrm{sec}$. The cover slips were air dried, mounted on glass slides and bacterial cells observed under a light microscope.

Effect of proteins and polysaccharides produced by probiotic bacteria and Ht-29 cells on adherence of pro- biotic bacteria to HT-29 cells. The probiotic bacteria were grown in MRS broth, the supernatant decanted and the cell pellets washed as described earlier. Each bacterial cell pellets was applied on to Ht-29 monolayer cells grown on glass cover slips inserted in plastic cell culture plates in order to determine the effect of proteins or polysaccharides produced by bacteria or colonic cells on adherence to Ht-29 cells. The experimental regime consisting of five treatments was as shown below:

(a) Cells in the original spent MRS broth (control),

(b) Washed bacterial cell pellet suspended in fresh MRS broth,

(c) Washed bacterial cell pellet suspended in spent MRS broth, and treated with trypsin to denature proteins,

(d) Washed bacterial cell pellet suspended in spent MRS broth, treated with sodium periodate to denature polysaccharides, and

(e) Washed bacterial cell pellet suspended in untreated spent MRS broth added to Ht-29 cells treated with sodium periodate.

Adherence levels of bacterial cells treated with trypsin or sodium periodate were compared with the control which was neither treated with trypsin nor with sodium periodate.

Treatment of spent broth and bacterial cells with trypsin. Ten millilitres of MRS spent broth supernatant was taken in a test tube, $0.1 \mathrm{ml}$ trypsin $(100 \mathrm{mg} /$ $\mathrm{ml}$ ) added and incubated at $37^{\circ} \mathrm{C}$ for $1 \mathrm{hr}$. After incubation, the content was mixed by vortexing for $1 \mathrm{~min}$, and $0.5 \mathrm{ml}$ of foetal calf serum (FCS) was added followed by incubation at $37^{\circ} \mathrm{C}$ for $1 \mathrm{hr}$ to inactivate trypsin.

Similarly, each bacterial cell pellet was suspended in $10 \mathrm{ml}$ of PBS in a test tube, $0.5 \mathrm{ml}$ of trypsin (100 $\mathrm{mg} / \mathrm{ml}$ ) was added and incubated at $37^{\circ} \mathrm{C}$ for $1 \mathrm{hr}$. The content was vortexed for $1 \mathrm{~min}, 0.5 \mathrm{ml}$ of FCS added and incubated at $37^{\circ} \mathrm{C}$ for $1 \mathrm{hr}$ to inactivate trypsin. The cell suspension was centrifuged $(5,000 \mathrm{rpm} ; 10$ $\mathrm{min}$ ) and the cell pellet was resuspended in fresh PBS.

Treatment of spent broths and bacterial cells with sodium periodate. Each bacterial cell pellet was suspended in $8 \mathrm{ml}$ of PBS. Two millilitre aliquot of $0.25 \mathrm{M}$ sodium periodate was added to the cell suspension and incubated at $37^{\circ} \mathrm{C}$ for $1 \mathrm{hr}$. The cells were centrifuged, washed 3 times with PBS and resuspended in PBS. One millilitre of the cell suspension was added to the monolayer and incubated at $37^{\circ} \mathrm{C}$ for $2 \mathrm{hr}$. The bacterial cell suspension was pipetted out and the monolayer was rinsed, fixed and stained as described earlier.

Fractionation of bacterial spent broth. Bacterial spent broths were fractionated using an Amicon ultra- 
filtration unit (Amicon Inc., Beverly, USA) and membranes (Sartorius AG, Germany) of 30,000 and 50,000 $\mathrm{kDa}$ molecular weight cut offs (MWCO). The ultrafiltration was carried out at $4^{\circ} \mathrm{C}$ to avoid microbial growth. The retentates and permeates were used for adherence studies. The retentate of 30,000 MWCO membranes was considered to be $>30,000 \mathrm{kDa}$, whereas the permeate was assumed to be smaller than $30,000 \mathrm{kDa}$. Similarly, the retentate of 50,000 MWCO membranes was considered to be $>50,000 \mathrm{kDa}$, whereas the permeate was smaller than 50,000 kDa.

Preparation of adherence specimens for electron microscopy. Each probiotic bacteria culture was allowed to adhere to $\mathrm{Ht}-29$ monolayer cells grown on plastic cover slips for $2 \mathrm{hr}$ and washed 6 times with PBS (pH 7.0). The specimens were fixed in $2.5 \%$ glutaraldehyde in $0.1 \mathrm{M}$ PBS for $30 \mathrm{~min}$ at room temperature $\left(20^{\circ} \mathrm{C}\right)$. After washing 4 times in buffer, the samples were post-fixed in $2 \%$ osmium tetroxide in water for $30 \mathrm{~min}$ at room temperature. The samples were washed twice in distilled water, dehydrated in a series of graded acetone solutions and embedded in aralditeepon resin. The blocks were polymerised at $60^{\circ} \mathrm{C}$ for $48 \mathrm{hr}$. Semithin sections $(1 \mu \mathrm{m})$ and ultrathin $(\sim 88 \mathrm{~nm})$ sections showing gold and silver interference colours were cut using an ultramicrotome (Model Om U2, Reichtert Microtome, Vienna, Austria). Semithin sections were mounted on glass microscope slides and stained with $1 \%$ solution of each of methylene blue and sodium tetraborate. The ultrathin sections were collected on acetone cleaned uncoated 200 mesh copper grids and stained with 5\% aqueous solution of uranyl acetate for $10 \mathrm{~min}$ and Reynold's lead citrate for 10 min. The sections were examined using a transmission electron microscope (Model 300, Philips, Einghoven, The Netherlands) at $60 \mathrm{kV}$, and at 33,000 and 55,000 magnifications.

\section{RESULTS AND DISCUSSION}

Level of Adherence of Probiotic Bacteria to HT-29 Cells

Table 1 shows the level of adherence of 15 strains of probiotic bacteria. In general, B. infantis 1912, $B$. longum 1941, and L. acidophilus 2400 and 2415 showed high levels of adherence followed by B. bifidum (1900, 1901), B. adolescentis 1920, and B. thermophilum 20210. Figure 1 shows the Ht-29 monolayer cells as seen under a light microscope at 100 magnification and Fig. 2 shows the levels of adherence of B. bifidum 1900, B. infantis 1912, B. longum 1941, and L. acidophilus 2400, 2409 and 2415. B. infantis 1912 and B. longum 1941 exhibited high levels of adherence among
Table 1. Comparison of the level of adherence to Ht-29 cells among probiotic bacteria.

\begin{tabular}{cc}
\hline Strain/species of bacteria & $\begin{array}{c}\text { No. of bacterial cells adhered } \\
\text { to Ht-29 cells }\end{array}$ \\
\hline Bifidobacterium spp. & $185 \pm 5^{\mathrm{a}}$ \\
1900 (B. bifidum) & $170 \pm 8$ \\
1901 (B. bifidum) & $665 \pm 15$ \\
1912 (B. infantis) & $180 \pm 12$ \\
1920 (B. adolescentis) & $32 \pm 7$ \\
1930 (B. breve) & $546 \pm 13$ \\
1941 (B. longum) & $73 \pm 14$ \\
20097 (B. longum) & $8 \pm 5$ \\
20099 (B. pseudolongum) & $195 \pm 17$ \\
20210 (B. thermophilum) & $105 \pm 13$ \\
Lactobacillus acidophilus & $12 \pm 4$ \\
2400 & $5 \pm 4$ \\
2401 & $4 \pm 3$ \\
2404 & $6 \pm 4$ \\
2405 & $380 \pm 17$ \\
2409 &
\end{tabular}

All strains of bacteria were used at a concentration of $1 \times 10^{6} \%$ $\mathrm{ml}$.

${ }^{\mathrm{a}}$ Mean \pm S.D. $(n=4)$.

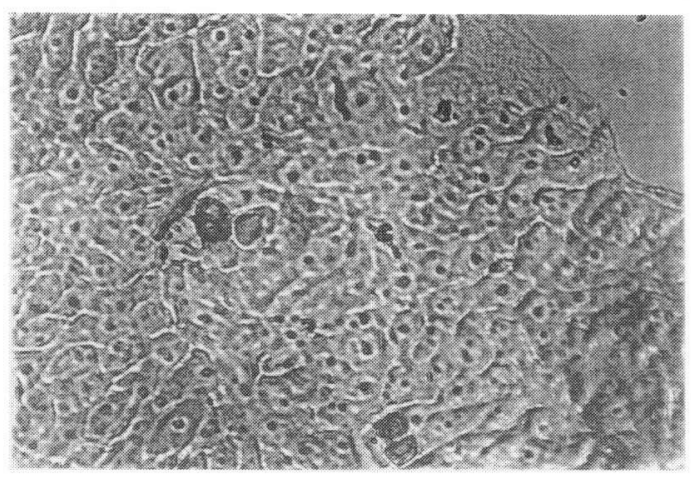

Fig. 1. Unstained Ht-29 monolayer cells as observed with the aid of a light microscope (magnification $\times 100$ ).

bifidobacteria. L. acidophilus 2415 showed higher level of adherence than 2400, whereas L. acidophilus 2409 adhered poorly.

Effects of Proteins and Polysaccharides on Adherence of Probiotic Bacteria to Ht-29 Monolayer Cells

Figure 3 shows the effect of proteins and polysaccharides on adherence of probiotic bacteria to $\mathrm{Ht}-29$ cells. For this part of the study, each bacterial suspension was used at a concentration of $10^{8} \mathrm{cfu} / \mathrm{ml}$. The figure shows the level of adherence of probiotic bacte- 


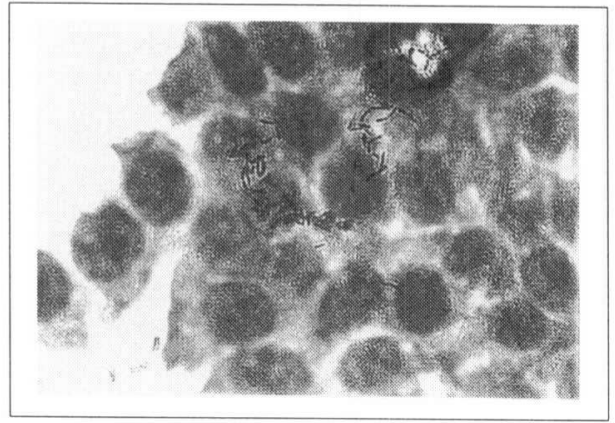

B. bifidum 1900

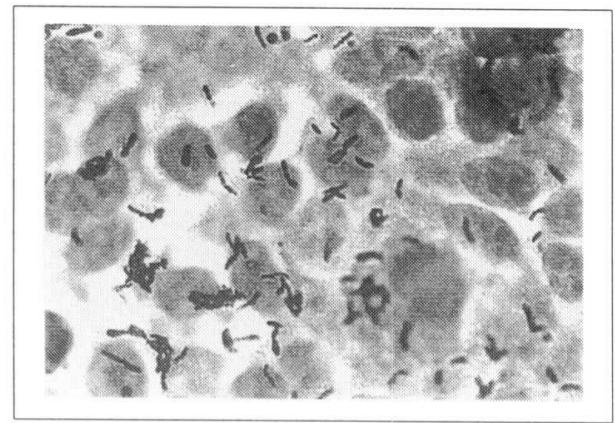

B. longum 1941

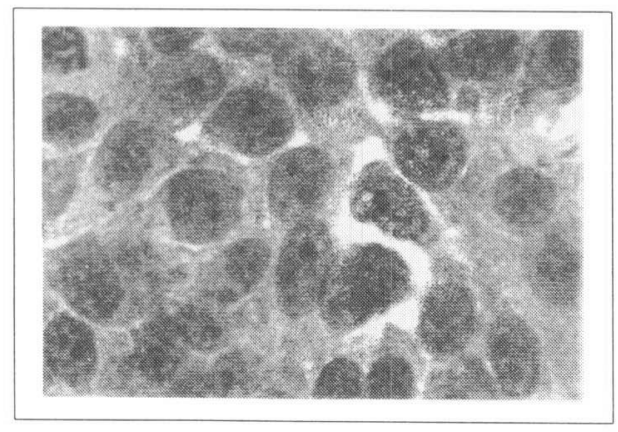

L. acidophilus 2409

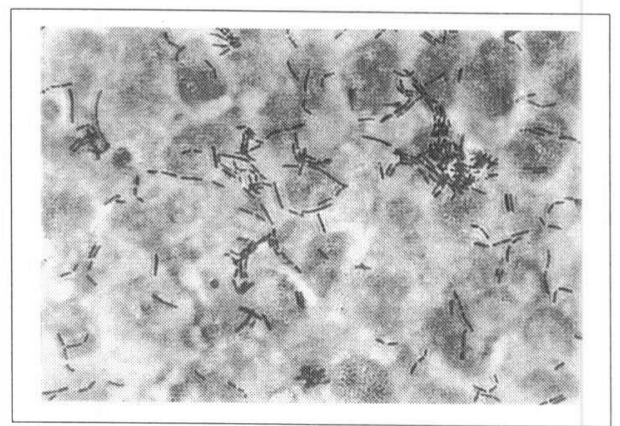

B. infantis 1912

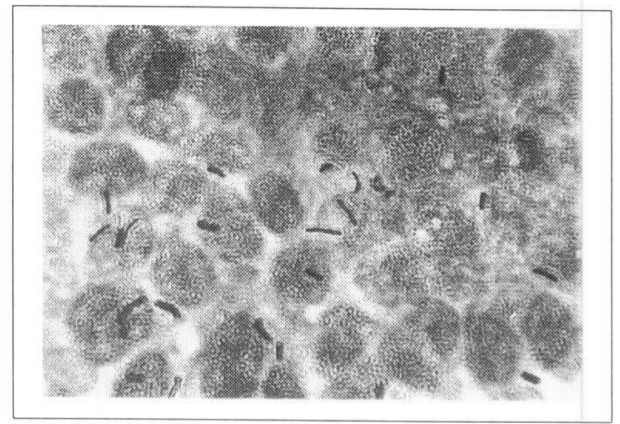

L. acidophilus 2400

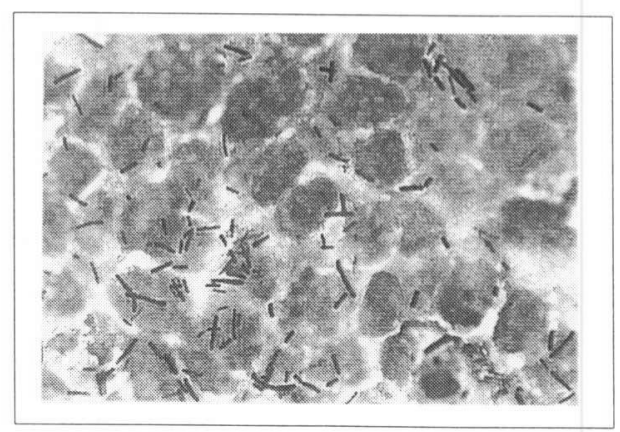

L. acidophilus 2415

Fig. 2. Adherence patterns of B. bifidum 1900, B. infantis 1912, B. longum 1941, L. acidophilus 2400, L. acidophilus 2409 and $L$. acidophilus 2415 to Ht-29 monolayer cells as observed using a light microscope (cells of each bacterial strains were suspended in spent broths at a concentration of $10^{6}$ $\mathrm{cfu} / \mathrm{ml})($ magnification $\times 1,000)$.

ria suspended in spent MRS broth treated with or without trypsin or sodium periodate which was added to Ht-29 cells.

As shown in the figure, cells of B. bifidum 1900, 1901 or $B$. thermophilum in spent or fresh MRS broth showed similar levels of adherence. This suggests that any component liberated into the spent broth during growth of this organism may not have been responsible for adherence. When the spent broth or bacterial cells were treated with trypsin or periodate, this organism showed less adherence. This could be due to the denaturation of proteins or polypeptide like substances produced in bacterial cell walls responsible for adherence. Similarly, when bacterial cells were treated with periodate to remove polysaccharides (treatment d), the number of adhering cells did not decrease as compared with the control. This suggests that bacterial polysaccharides may not have been involved in adherence. When Ht-29 monolayer cells were treated with periodate to remove polysaccharides from cell surfaces, the number of ad- 


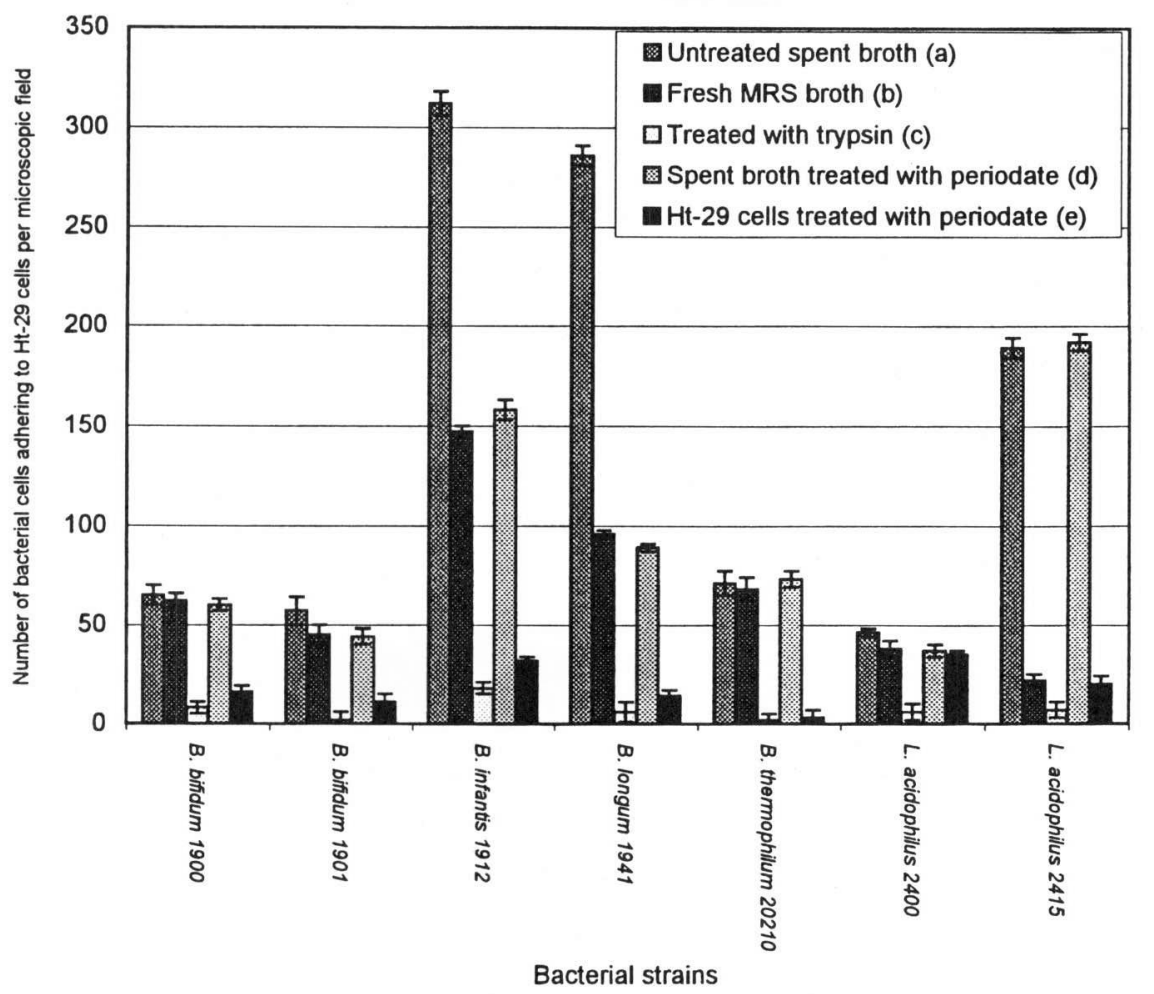

Fig. 3. Levels of adherence of probiotic bacteria to Ht-29 monolayer cells after various treatments of the cells and spent broths.

hering cells decreased to $<25 \%$ (treatment e), which suggests that polysaccharide like substance produced by Ht-29 monolayer cells may have played an important role in adherence of $B$. bifidum 1900, 1901 or $B$. thermophilum 20210.

B. infantis 1912 showed a high level of adherence (Fig. 3) and there was an even distribution of adhering cells over the Ht-29 monolayer cells (Fig. 4a). However, when bacterial cells were suspended in fresh MRS broth and applied on to the monolayer cells, the number of adhering cells reduced to $<50 \%$ and a large number of cells were limited to patches of monolayer cells (treatment b in Fig. 3; Fig. 4b). A high reduction in adherence of $B$. infantis 1912 upon treatment with trypsin was observed (treatment c in Fig. 3; Fig. 4c). When bacterial cell suspension in spent broth was treated with periodate, the number of adhering bacteria was similar to that treated with fresh MRS broth. Further reduction in adhering bacteria was observed when Ht-29 monolayer cells were treated with periodate (treatment e in Fig. 3; Fig. 4e). These observations suggest that a protein or polypeptide like substance present in cell walls of bacteria and polypeptides of bacteria of $\mathrm{Ht}-29$ monolayer cells seemed to be involved in adher- ence of this organism. B. longum 1941 also exhibited a similar pattern as with B. infantis 1912 (Fig. 3).

L. acidophilus 2415 cells suspended in untreated spent broth (control) showed a higher level of adherence. When the cells were suspended in fresh MRS broth, adherence of $L$. acidophilus 2415 to $\mathrm{Ht}-29$ monolayer cells reduced by about $90 \%$. Treatment with trypsin also showed no adherence. Treatment of bacterial cells with periodate did not affect the level of adherence. However, treatment of $\mathrm{Ht}-29$ monolayer cells with periodate reduced the number of adhering cells by about $80-90 \%$. These observations suggest that a protein or polypeptide substance in spent broth was directly involved in adherence of $L$. acidophilus 2415 . Further, polysaccharides of Ht-29 monolayer cells seemed to be involved in the adherence of this organism.

Effect of Various Molecular Size Fractions of Supernatant of Spent Broth in Adherence of Selected Strains of Probiotic Bacteria to Ht-29 Monolayer Cells

Figure 5 shows the effect of various molecular weight fractions of supernatant of spent broth on the adherence of B. infantis 1912, B. longum 1941, and L. aci- 


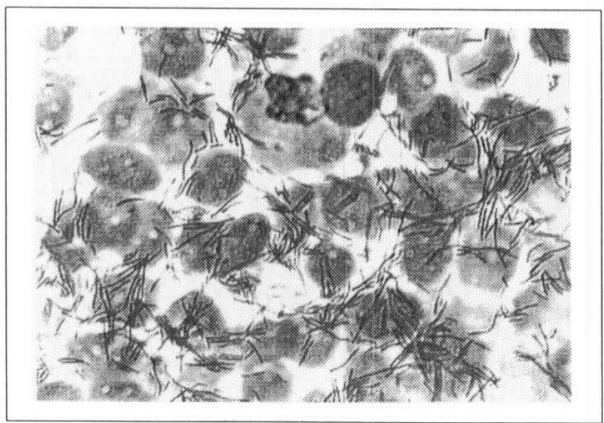

Control (a)

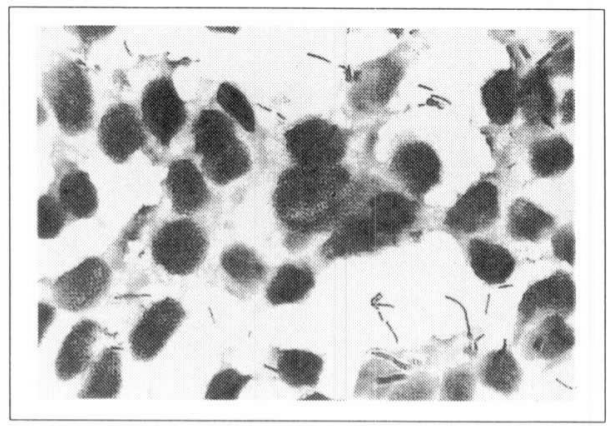

Treatment (c)

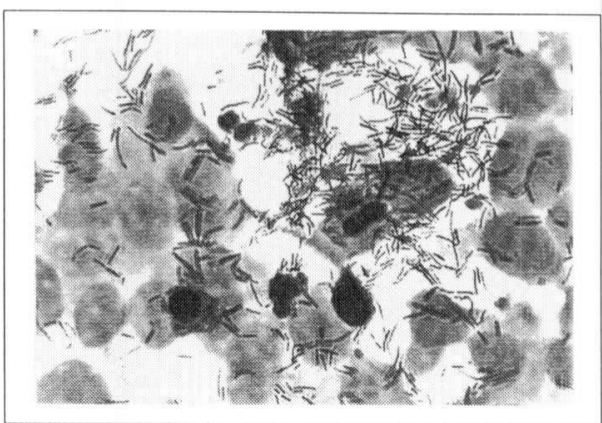

Treatment (b)

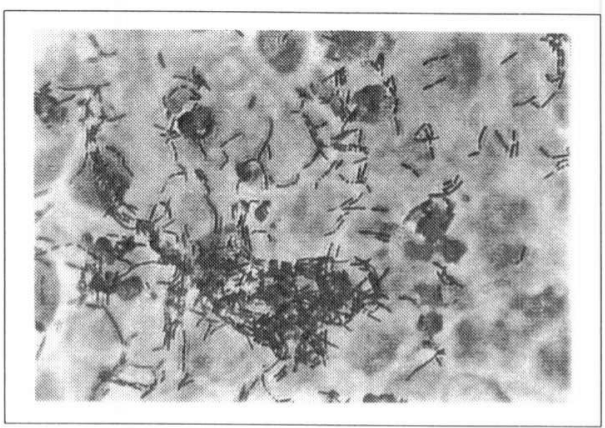

Treatment (d)

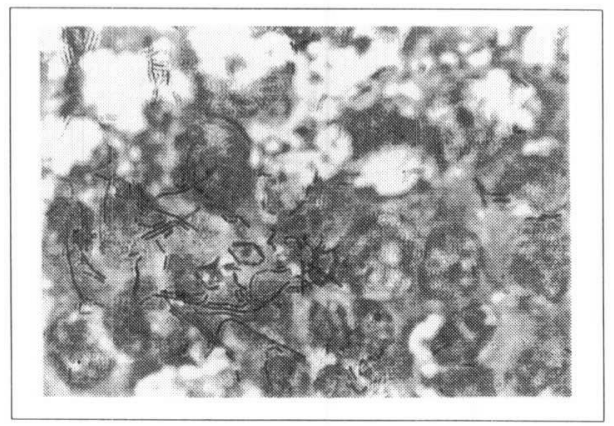

Treatment (e)

Fig. 4. Adherence of B. infantis 1912 to Ht-29 monolayer cells after various treatments. (a) untreated broth, (b) fresh broth, (c) spent broth treated with trypsin, (d) spent broth treated with periodate and (e) Ht-29 cells treated with periodate.

dophilus 2415. Non-fractionated supernatant of spent broth, and fraction b $(>50,000 \mathrm{kDa})$ and $\mathrm{c}(<50,000$ $\mathrm{kDa}$ ) of $B$. infantis 1912 showed similar levels of adherence. Fraction d (30,000-50,000 kDa) showed highest level of adherence, and almost all $\mathrm{Ht}-29$ cells in the monolayer cells were covered by the bacterial cells. However, fraction e $(<30,000 \mathrm{kDa})$ showed lower levels of adherence as compared to fraction d. These observations showed that best adherence was achieved with a protein of molecular size of 30,000-50,000 kDa.

The supernatant (fraction a) of whole spent broth of B. longum 1941 showed much higher level of adherence as compared with the fraction b containing molecules larger than $50,000 \mathrm{kDa}$. With the fraction c $(<50,000 \mathrm{kDa})$ and $\mathrm{d}(30,000-50,000 \mathrm{kDa})$, the bacterial cells showed similar levels of adherence as with fraction a. However, with fraction e $(<30,000 \mathrm{kDa})$, the level of adherence reduced substantially. These ob- 


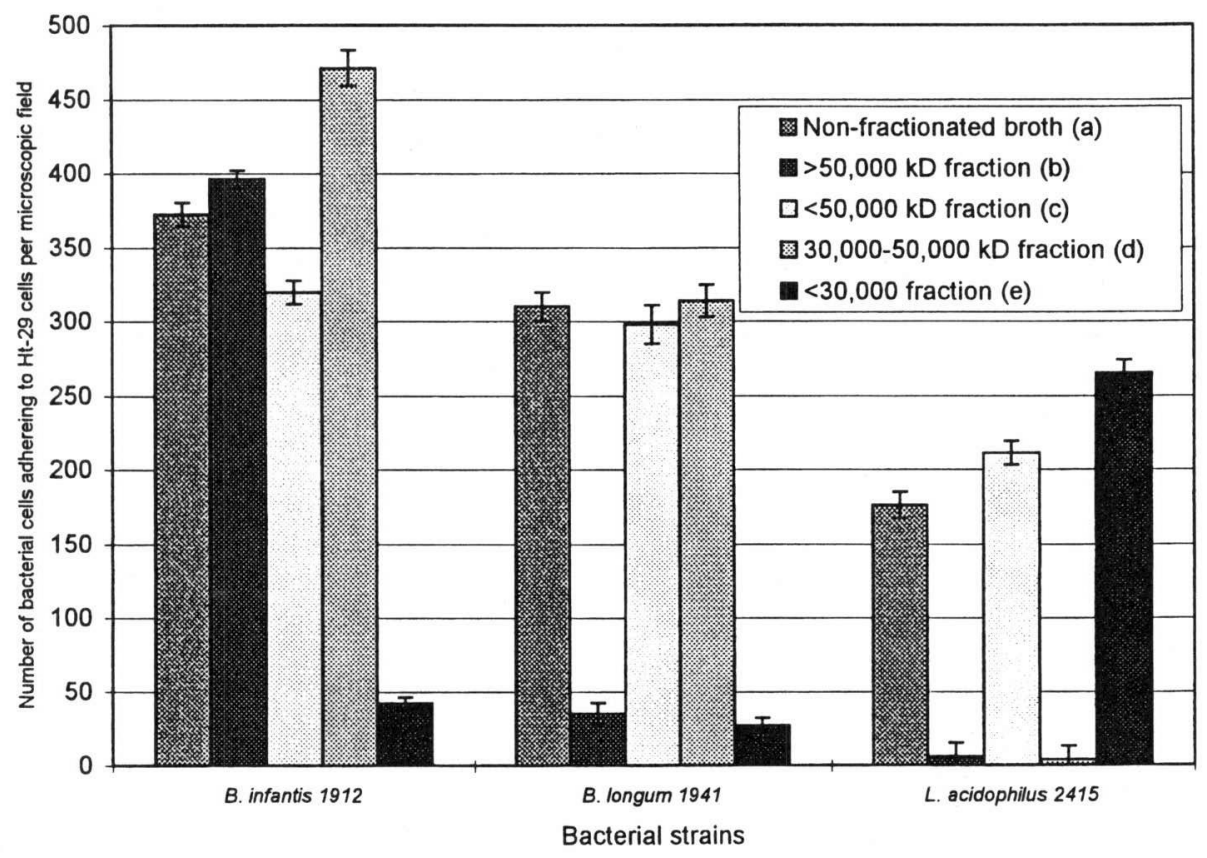

Fig. 5. Levels of adherence of probiotic bacteria to Ht-29 monolayer cells after applying with various molecular size fractions of spent broths.

servations suggest that the protein present in the spent broth responsible for adherence was of molecular size between 30,000 and 50,000 kDa.

For $L$. acidophilus 2415 fraction b with a molecular size $>50,000 \mathrm{kDa}$ did not produce any adherence (treatments b in Figs. 5 and 6) and fraction of $<30,000 \mathrm{kDa}$ showed the highest level of adherence as compared with those produced by fractions a and $\mathrm{c}$. This suggests that the adherence of $L$. acidophilus 2415 was supported by a protein of $<30,000 \mathrm{kDa}$.

Thus, it appears that different probiotic bacteria adhered to intestinal surfaces at different levels. Proteins of bacterial origin and polysaccharides produced by $\mathrm{Ht}-$ 29 cells seemed to be responsible for adherence of probiotic bacteria.

Electron Microscopic Study of Adherence of Selected Strains of Probiotic Bacteria

Figures 7-9 illustrate the adherence of these bacteria to $\mathrm{Ht}-29$ mono-layer cells. Specimens were sliced vertically and the electron micrographs were taken using a transmission electron microscope.

Figure 7 shows a vertical cross section of an adhering probiotic bacterial cell (B. infantis 1912) to an Ht29 mono-layer cell. The adherence seemed to be caused by deep embedding of the bacterial cell to the surface of Ht-29 cell. A thick layer possibly of polysaccharide- protein structure is also evident between the two types of cells. Polysaccharides-protein is known to give strong binding between two cells. Figure 8 shows the formation of an inter-cellular bridge between a probiotic cell (B. adolescentis 1920) and an Ht-29 cell. The bridge seemed to be extended from the Ht-29 cells. Figure 9 shows the attachment of a B. bifidum 1900 cell to an Ht-29 cell. The formation of a wide bridge between the two cells is visible.

Thus, the electron micrographs confirmed that intercellular bridging material was formed when probiotic cells were attached to the Ht-29 mono-layer cells. This material could be protein in nature or a protein-polysaccharide like substance originating from the bacterial cells and from $\mathrm{Ht}-29$ cells.

\section{REFERENCES}

(1) Bernet FM, Brassart D, Neeser JR, Servin A. 1993. Adhesion of human bifidobacterial cells to cultured human intestinal epithelial cells and inhibition of enteropathogen cell interactions. Appl Environ Microbiol 59: 4121-4128.

(2) Coconnier MH, Klaenhammer TR, Kerneis S, Bernet MF, Servin AL. 1992. Protein mediated adhesion of Lactobacillus acidophilus $\mathrm{BG} 2 \mathrm{FO} 4$ on human enterocyte and mucus secreting cell lines in culture. Appl Environ Microbiol 58: 2034-2039.

(3) Fuller R. 1989. Probiotics in man and animals. J Appl Bacteriol 66: 365-378. 


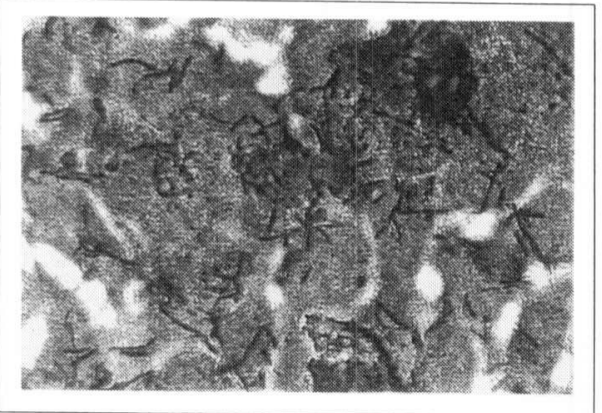

(a) Control

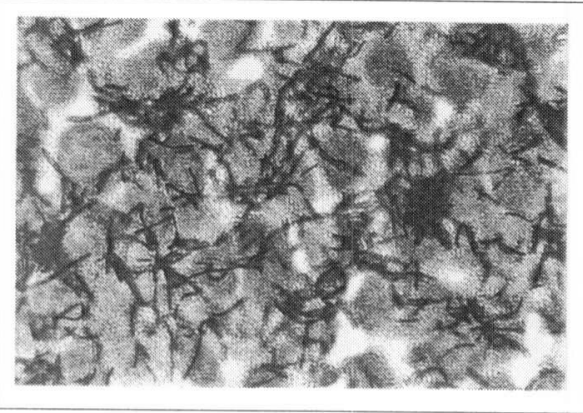

(c) In fraction $<50,000 \mathrm{kD}$

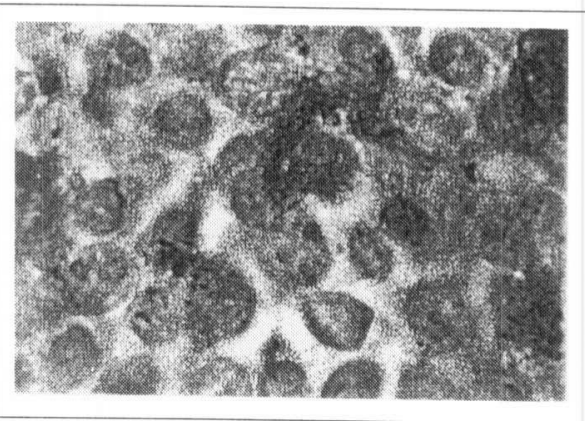

(b) In fraction $>50,000 \mathrm{kD}$

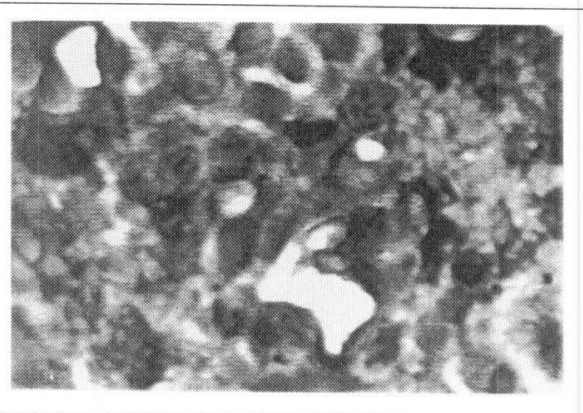

(d) In fraction 50,000-30,000 kD

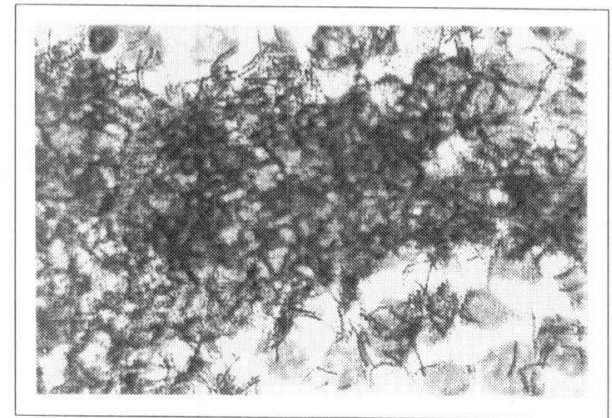

(e) In fraction $<30,000 \mathrm{kD}$

Fig. 6. Levels of adherence of L. acidophilus 2415 to $\mathrm{Ht}-29$ monolayer cells after applying to the latter with various molecular size fraction of spent broth. Note the absence of any adhering cells when fraction 50,000-30,000 kDa was used. The fraction $<30,000 \mathrm{kDa}$ and $<50,000 \mathrm{kDa}$ supported best adherence.

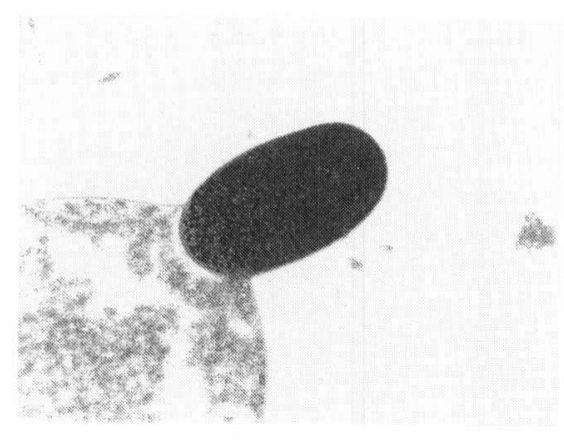

Fig. 7. Transmission electron micrograph of a vertical cross section of an adhering probiotic bacterial cell (B. infantis 1912) to an Ht-29 monolayer cell (magnification $\times 55,000)$. 


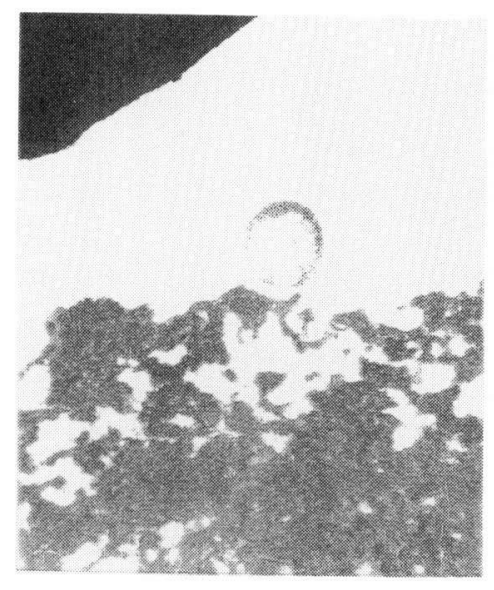

Fig. 8. Transmission electron micrograph of a vertical cross section illustrating formation of intracellular bridge between B. adolescentis 1920 and an Ht-29 cell (magnification $\times 33,000)$

(4) Mukai T, Arihara K. 1994. Presence of initial lectin binding glycoproteins on the cell surface of Lactobacillus acidophilus. Biosci Biotech Biochem 58: 1851-1854.

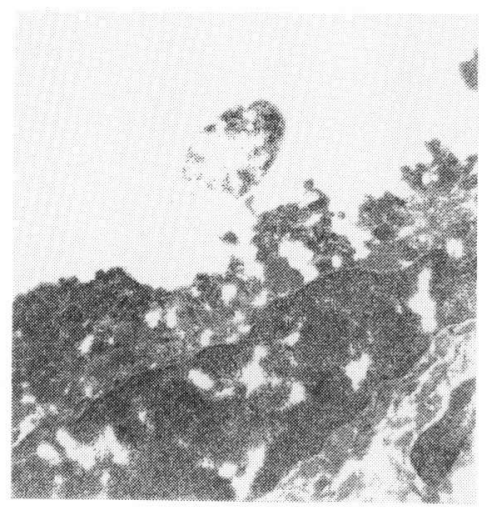

Fig. 9. Transmission electron micrograph of a vertical cross section illustrating formation of intracellular bridge between B. bifidum 1900 and an Ht-29 cell (magnification $\times 33,000$ ).

(5) Simon GL, Gorbach SL. 1986. The human intestinal microflora. Dig Dis Sci 31: 1475-1625. 